\title{
Conditioned context aversion learning in the laboratory mouse
}

\author{
Sezen Kislal ${ }^{1}$ • David A. Blizard ${ }^{1}$
}

Published online: 9 March 2016

(C) Psychonomic Society, Inc. 2016

\begin{abstract}
It is well known that pairing of large contextual changes with illness can cause conditioned context aversion in laboratory rats. The aim of present study was to develop a paradigm to study this phenomenon in laboratory mice, a species widely employed in neurobehavioral studies. Genetically heterogeneous mice, drinking from plastic bottles in the colony room, learned to avoid glass bottles after a single conditioning trial when drinking from these was paired with injections of lithium chloride. The aversion was independent of any difference in the taste of water in plastic vs. glass bottles. When the variation in the visual stimulus was less distinct, development of a strong aversion required two conditioning trials and was not retained as well. The results also showed that conditioned context aversion, just like conditioned taste aversion, could also be developed across a 30-minute CS-UCS delay. The fact that taste was not a factor in distinguishing drinking from glass and plastic water bottles raises the possibility that, contextual stimuli, not taste, may have been the CS when rats (in Garcia's original experiments) avoided drinking from plastic bottles that had been paired with radiation. The development of contextual aversion conditioning protocols for mice will enable the molecular resources available for this species to be exploited. Furthermore, representation of the CS by
\end{abstract}

This research was supported by Ford Endowment Award from the College of Health and Human Development.

Sezen Kislal

sezenkislal@gmail.com

David A. Blizard

dab22@psu.edu

1 Department of Biobehavioral Health, Pennsylvania State University, 221 Biobehavioral Health Building, University Park, PA 16802, USA discrete rather than the multimodal CSs typically used in most studies on contextual conditioning offers more focus when considering its neuroanatomical basis.

Keywords Context aversion learning $\cdot$ Classical conditioning

In early observations that led to the discovery of the phenomenon of conditioned taste aversion learning (CTA), Garcia showed that rats that were radiated in the presence of plastic bottles developed an aversion to drinking from those containers. On the other hand, concurrently, they drank normal amounts from the glass bottles that were used in the colony room which had not been paired with radiation (Garcia 1954; Reilly \& Schachtman, 2009). Garcia speculated that the water in the plastic bottles tasted differently than the water from the glass bottles and that it was this variation that provided the conditioned stimulus (CS) for their aversion (Garcia 1954). In later experiments, he showed that rats developed long-lasting aversions to the taste of saccharin when paired with radiation (conditioned taste aversion), thus seeming to support his interpretation of what may be crudely called the "plastic water" experiment (Garcia, Kimeldorf, \& Koelling, 1955; Revusky \& Garcia, 1970).

The tendency to acquire aversions to contextual stimuli when these are paired with illness has since been well demonstrated (Boakes, Westbrook, Elliott, \& Swinbourne, 1997; Revusky \& Parker, 1976; Rodriguez, Lopez, Symonds, \& Hall, 2000; Stockhorst, Steingrueber, Enck, \& Klosterhalfen, 2006; Ursula, Paul \& Sibylle, 2007). Laboratory rats have been the main subject of these studies (Boakes et al., 1997; Revusky \& Parker, 1976; Rodriguez et al., 2000), although other species have been used (Cusato \& Domjan, 1998). However, in the last 20 or so years, laboratory mice have become the principal tool for neurobehavioral studies, and 
the purpose of the present experiments is to develop a context aversion conditioning paradigm for use in this species. This would permit the molecular resources available for use with mice to be exploited for the analysis of this kind of learning (Bertaina-Anglade, Tramu, \& Destrade, 2000; Swank, Ellis, \& Cochran, 1996; Tang et al., 1999).

While studying CTA in mice (Blizard, 2007; Blizard \& McClearn, 2000), control mice (those that drank water from novel tubes) exhibited strong conditioned aversions to the novel containers following pairing with lithium chloride $(\mathrm{LiCl})$, raising the possibility that they had developed aversions to the containers. The present experiments were conducted to formally examine this possibility. All of the stimuli were presented in the home cage of the mouse, a procedure that may enhance the ability of the experimental subject to detect novel stimuli as a deviation from a very familiar environment.

\section{Experiment 1}

In our first experiment, differences between plastic and glass bottles were employed as the contextual variation. It also included an evaluation of the potential role of differences in the taste of water from the two containers in any aversion that was established. Mice were maintained on tap water from plastic bottles, and illness was induced after drinking water from glass bottles. This is the opposite configuration of that used by Garcia (plastic to glass bottles rather than glass to plastic), but it was adopted because it is very difficult to measure water intake accurately from plastic bottles. In any case, it was predicted that mice would develop conditioned aversions to one or more features that differ between plastic and glass bottles, and this aversion would be reflected in reduced water intakes when drinking from glass bottles. A "plastic water" control group was also included that drank from glass bottles containing water decanted from plastic bottles just before the conditioning trial. If, as suggested by Garcia, the difference between taste of water in the glass versus the plastic bottles was a key feature underlying conditioning, this group should not develop a conditioned aversion.

\section{Method}

The following methods and procedures are common to all three experiments and have been approved by the IACUC (Institutional Animal Care and Use Committee) of The Pennsylvania State University.

\section{Colony room}

A 12/12-hr light/dark cycle (lights on $0500-1700 \mathrm{hrs}$ ) was maintained, and temperature was kept at $72^{\circ} \mathrm{F}+/-2$. There was no natural light in the room. Mice were housed in plastic cages (height: $12 \mathrm{~cm} \times$ width: $18 \mathrm{~cm} \times$ length: $29.5 \mathrm{~cm}$ ) with wire tops for the whole experiment. Rodent Lab Diet 5001 (PMI International; Brentwood, MO), as well as tap water, were available ad libitum during the experiments, except when animals were water restricted, as described below.

\section{Subjects}

The subjects were 45 genetically heterogeneous mice (mean age 93 days, range: $87-100$ ) from an advanced intercross (AI) of C57BL/6J (B6) and DBA/2J (D2) strains. There were 20 different litters. Sex (24 male, 21 female) and litter membership was evenly distributed across the three experimental groups (15/group). Body weights were recorded at the beginning and end of the experiments.

\section{Training to drink}

As shown in Fig. 1 (Adaptation), group-housed mice were individually caged and continued to drink tap water for 1 week from pint-sized translucent plastic bottles with blue plastic lids and metal spouts. Mice were then trained to drink water promptly from the same bottles (Drink Training) in the light phase of the circadian cycle by depriving them of water at 5:00 p.m.; giving them access to water for 30 minutes on two occasions, at 9:00 a.m. and 12:00 p.m. the following day; and then allowing them to drink from 2:00 p.m. until 5:00 p.m. (the beginning of the dark phase). This procedure was repeated on 3 consecutive days (see Fig. 1).

\section{Conditioning procedure}

Following drink training with the plastic bottles, three context aversion conditioning (CCA) trials were carried out at 2-day intervals (see Fig. 1). After 16 hours of water deprivation, water was presented in pint-sizes glass bottles with rubber stoppers and stainless steel (SS) spouts with ball-bearings to all mice in their home cage. Mice in the $\mathrm{NaCl}$ control group (PB-GB ${ }^{\mathrm{TW} / \mathrm{NaCl}}$; see Table 1 for an explanation of abbreviations) drank tap water and were injected intraperitoneally (IP) with sodium chloride $(\mathrm{NaCl} ; 0.15 \mathrm{M}, 0.3 \mathrm{~mL} / 10$ grams body weight) after $10 \mathrm{~min}$ access. Mice in the experimental group (PB-GB ${ }^{\mathrm{TW} / \mathrm{LiCl}}$; see Table 1) also drank tap water and were injected with $\mathrm{LiCl}$ (at the same molar concentration and dose as $\mathrm{NaCl}$ ). A third group (also injected with $\mathrm{LiCl}$ ), included to control for the possible contribution of the taste of water in plastic bottles, was presented with glass bottles containing water decanted from plastic bottles (the water had been held in the plastic bottles for at least 48 hours) immediately before the trial (PB-GB ${ }^{\mathrm{PW} / \mathrm{LiCl}}$; see Table 1). The CS bottles were removed from the cages 10 minutes after the injection, and then water intake was immediately measured. Water consumption of each mouse was determined by weighing the 


\section{Days}

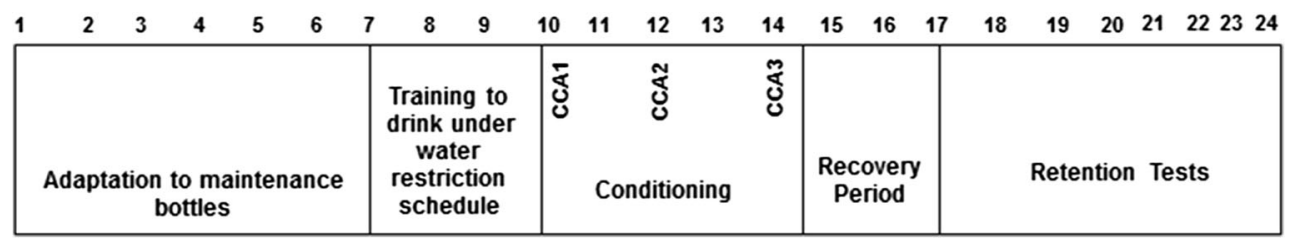

Fig. 1 The general procedure that we used in our experiments. The experiment consisted of five phases: adaptation, drink training, conditioning, recovery, and retention. Note. Top row: Please note that the number of days devoted to retention phase varied by experiment

water bottles at the start and finish of the conditioning. Pilot studies had shown that if the bottles were completely filled (to minimize the amount of air left inside), accurate water intake could be measured. Their regular plastic bottles were returned to the home cage 20 minutes after the CS tubes were removed from cages. On the intervening days, the animals had ad libitum access to water in their regular plastic bottles.

Following the completion of the recovery period (ad lib food and water in plastic bottles), a retention test was carried out 7 days after CCA3. The CS bottles were presented to mice for 42 minutes after 16 hours water deprivation; water intake was recorded.

\section{Data analyses}

Intake data were entered into an Excel spreadsheet and analyzed using SPSS (Version 20, IBM). The primary tool was analysis of variance. The alpha level was set at $p<.05$. Statistical significances were reported as <.05, <.01, <.001. Sex was included as a factor in all experimental analyses; however, it was never statistically significant and did not interact with other factors. Thus, it is not mentioned in the individual experimental reports.

\section{Results}

\section{Conditioning}

Analyses of variance of water intakes during conditioning involved two between-subjects factors, Group (Control, TW, and PW) and Sex (Male and Female), as well as a withinsubjects factor (Trials, 3). Bonferonni protection was used during post hoc tests.

There was a significant main effect for Group, reflecting the fact that PB-GB ${ }^{\mathrm{PW} / \mathrm{LiCl}}$ and PB-GB ${ }^{\mathrm{TW} / \mathrm{LiCl}}$ groups had significantly lower intake levels than the $\mathrm{NaCl}$ control group, $F(2,41)=30.51, p<.001$, and Trials with water intake levels decreasing across the trials, $F(2,82)=26.80, p<.001$ (see Fig. 2). In addition, a significant Group $\times$ Trials interaction, $F(4,82)=10.23, p<.001$, was observed. The interaction was assessed by performing a one-way ANOVA on each trial. As expected, there was no significant difference among the groups on CCA1, $F(2,43)=0.35, p=.7$ (see Fig. 2). However, there was a significant difference between the groups, $F(2,43)=34.22, p<.001$, on CCA 2 : the $\mathrm{NaCl}$ Control group had significantly higher intake than both PB$\mathrm{GB}^{\mathrm{PW} / \mathrm{LiCl}}$ and PB-GB ${ }^{\mathrm{TW} / \mathrm{LiCl}}$ groups (vs. PB-GB ${ }^{\mathrm{TW} / \mathrm{LiCl}}, p<$ .001 ; vs. PB-GB ${ }^{\mathrm{PW} / \mathrm{LiCl}} ; p<.001$; see Fig. 2 ), whereas there was no significant difference between the PB-GB ${ }^{\mathrm{PW} / \mathrm{LiCl}}$ and PB-GB ${ }^{\mathrm{TW} / \mathrm{LiCl}}$ groups $(p=.12)$. A similar finding was found on CCA3, $F(2,43)=30.52, p<.001$, the PB-GB ${ }^{\mathrm{PW} / \mathrm{LiCl}}$ and PB-GB ${ }^{\text {TW/LiCl }}$ groups had significantly lower intakes than the $\mathrm{NaCl}$ control group $\left(\mathrm{NaCl}\right.$ control group vs. $\mathrm{PB}-\mathrm{GB}^{\mathrm{TW} / \mathrm{LiCl}}, p$ $<.001$, vs. PB-GB ${ }^{\mathrm{PW} / \mathrm{LiCl}} ; p<.001$; see Fig. 2), whereas the PB-GB ${ }^{\mathrm{PW} / \mathrm{LiCl}}$ and PB-GB ${ }^{\mathrm{TW} / \mathrm{LiCl}}$ groups were not significantly different from each other $(p=.45)$, reflecting the fact that water intakes were similar in both groups after the first conditioning trial. In addition, each group was separately examined using a repeated measures ANOVA. There was no main effect for Trials in the $\mathrm{NaCl}$ control group, $\mathrm{PB}-\mathrm{GB}{ }^{\mathrm{TW}} /$ ${ }^{\mathrm{NaCl}}, F(2,28)=1.07, p=.35$, reflecting the fact that $\mathrm{NaCl}$ control group's water intakes were similar throughout conditioning, whereas a Trial effect was observed in both PB-GB ${ }_{\mathrm{PW} / \mathrm{LiCl}}$ and PB-GB ${ }^{\mathrm{TW} / \mathrm{LiCl}}$ groups, PB-GB ${ }^{\mathrm{PW} / \mathrm{LiCl}}, F(2,28)=$ 9.07, $p<.01$, and PB-GB ${ }^{\text {TW/LiCl }}, F(2,26)=44.47, p<.001$. Taken together, these results reflect the fact that the $\mathrm{NaCl}$ control group's water intakes were similar throughout conditioning, whereas the water intake levels for PB-GB ${ }^{\mathrm{PW} / \mathrm{LiCl}}$ and PB-GB ${ }^{\mathrm{TW} / \mathrm{LiCl}}$ groups decreased from CCA1 to CCA2 and CCA3 (see Fig. 2). Finally, a repeated measures ANOVA was

Table 1 Experimental groups $(N=15)$ and the bottle configurations for Experiment 1

\begin{tabular}{lllll}
\hline Groups & Regular Tubes & CS & Injection & Abbreviation \\
\hline NaCl Control Group & Plastic Bottle & Glass Bottle-Tap water & NaCl & PB-GB \\
Plastic Water Control Group & Plastic Bottle & Glass Bottle-Plastic water & LiCl & PB-GB $^{\text {PW/LiCl }}$ \\
Experimental Group & Plastic Bottle & Glass Bottle-Tap water & LiCl & PB-GB $^{\text {TW/LiCl }}$ \\
\hline
\end{tabular}


Development of aversion to glass bottles by mice maintained on plastic bottles

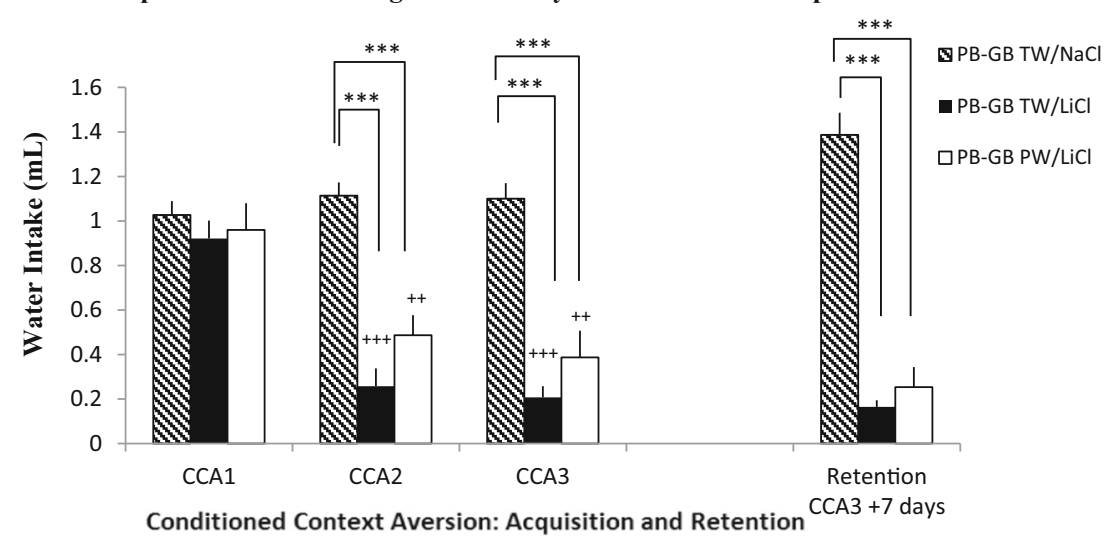

Fig. 2 B6/D2 AI mice maintained on plastic bottles (PB) were given three conditioning trials in which drinking from glass bottles (GB) was paired with $\mathrm{NaCl}$ (controls) or LiCl. PB-GB ${ }^{\mathrm{TW} / \mathrm{LiCL}}$ and PB-GB ${ }^{\mathrm{PW} / \mathrm{LiCl}}$ groups (see Table 1 for an explanation of abbreviations) showed high

applied to CCA2 and CCA3 for each PB-GB ${ }^{\mathrm{PW} / \mathrm{LiCl}}$ and PB$\mathrm{GB}^{\mathrm{TW} / \mathrm{LiCl}}$ group. There was no main effect for Trials in either analysis, reflecting the fact that there was no significant water intake reduction from $\mathrm{CCA} 2$ to $\mathrm{CCA} 3$ in either group, $\mathrm{PB}-\mathrm{GB}$ ${ }^{\mathrm{PW} / \mathrm{LiCl}}, F(1,14)=0.98, p=.34$, and PB-GB ${ }^{\mathrm{TW} / \mathrm{LiCl}}, F(1,13)$ $=0.6, p=.45$.

\section{Retention}

A two-factor ANOVA was conducted of water intake on the single retention test with Group and Sex as between-groups factors. There was a main effect for Groups, $F(2,41)=71.35$, $p<.001$. Post hoc analysis incorporating Bonferroni protection indicated that the $\mathrm{NaCl}$ control group had significantly higher intake than the PB-GB ${ }^{\mathrm{PW} / \mathrm{LiCl}}$ and PB-GB ${ }^{\mathrm{TW} / \mathrm{LiCl}}$ groups (in both cases, $p<.001$; see Fig. 2), whereas there was no significant difference between the plastic water control and experimental group (PB-GB ${ }^{\mathrm{PW} / \mathrm{LiCl}} \mathrm{vs}$. $\mathrm{PB}-\mathrm{GB}^{\mathrm{TW} / \mathrm{LiCl}}, p$ $=.1$; see Fig. 2), reflecting the fact that the aversion was similar in both PB-GB ${ }^{\mathrm{PW} / \mathrm{LiCl}}$ and PB-GB ${ }^{\mathrm{TW} / \mathrm{LiCl}}$ groups.

\section{Discussion}

Conditioned context aversion was clearly observed in Experiment 1; animals maintained on plastic bottles developed conditioned aversions to glass bottles when paired with LiCl. In addition, conditioned context aversion (decreased water intake from CS) was well retained for at least 7 days in both experimental groups. The fact that there were no statistically significant difference between the experimental groups in either conditioning trials or during the retention test is not consistent with a role for the flavor of water from plastic bottles influencing the strength of conditioning. aversion to drinking from the glass bottles (CS) after a single trial which was sustained for 7 days. $* * * p<.001$, compared to control group intakes. $++p<.01,+++p<.001$, compared to intake of same group on CCA1

\section{Experiment 2}

The findings of Experiment 1 provided good support for the hypothesis that alterations in the cage environment (plastic vs. glass water bottles of similar size and shape) can serve as CSs in an aversion conditioning paradigm. The present experiment was carried out to examine the role of another contextual difference between maintenance and conditioning conditions and to provide more evidence that a change in the taste of water is not necessary to cause context aversion in mice. In this study, mice were maintained on tap water in glass bottles or graduated tubes with light-colored tape. During conditioning, graduated tubes with a piece of dark-colored (DT) tape attached to the tube near the spout were presented to the mice. Thus, there were large differences (glass bottle vs. a graduated tube) distinguishing maintenance conditions and those present during conditioning in one comparison and small differences (graduated tube with light-colored tape vs. graduated tube with dark-colored tape) in the other.

It was predicted that mice would develop aversions to graduated glass tubes with dark-colored tape (after maintenance on glass bottles), thus ruling out a major influence of the taste of water in context conditioning (because both tubes had rubber stoppers and contained tap water). Less certainly, it was predicted that animals maintained on graduated tubes with lightcolored tape would develop aversions to tubes with darkcolored tape. Finally, it was predicted that there would be evidence for more effective conditioning when the differences between maintenance containers and those used during conditioning were greater.

\section{Method}

The subjects were $51 \mathrm{~B} 6 / \mathrm{D} 2$ AI mice (mean age 145 days, range: 140-150) from 17 different litters. Sex (24 male, 27 
female) and litter membership was evenly distributed across the three experimental groups (17/group).

Before the experiment, mice were routinely maintained on pint-sized translucent plastic bottles with blue plastic lids and metal spouts. Mice were then adapted to two different kinds of water containers for 5 days. One group $(N=17)$ drank from 25 $\mathrm{mL}$ graduated tubes with a piece of light-colored tape near the spout, a rubber stopper, and a stainless steel (SS) spout with a ball-bearing to prevent leakage, and the remaining mice $(N=$ 34) drank from pint size regular glass bottles with rubber stoppers and a pinhole SS spout (see Table 2). All mice were then trained to drink promptly from their maintenance tubes under water restriction, as previously described (see Experiment 1).

\section{Conditioning procedure}

During conditioning trials, graduated tubes (ball-bearing spout) with a piece of dark-colored tape attached to the tube near the spout were presented to the mice. Trial duration and injection procedures were the same as described for Experiment 1. Experimental groups (LT-DT ${ }^{\mathrm{LiCl}}$ and GB-DT LiCl; see Table 2 for an explanation of abbreviations) were injected intraperitoneally (IP) with $\mathrm{LiCl}$, and the control group (GB-DT ${ }^{\mathrm{NaCl}}$; see Table 2) was injected with $\mathrm{NaCl}$ during three conditioning trials.

Retention tests (42 minutes in duration) were carried out twice (CCA $3+3$ and CCA $3+13$ days) after conditioning. In addition, as a test of specificity, the maintenance containers were presented in a trial conducted on CCA $3+10$ days.

\section{Results}

\section{Conditioning}

Analyses of variance of intakes involved two betweensubjects factors, Groups (Control, GB, and LT) and Sex (Male and Female) and a within-subjects measure (Trials, 3). Bonferroni protection was used during follow-up tests.

Experimental groups had significantly lower intake than the control group (Groups, F2, $48=17.33, p<.001$ ) and water intake decreased across trials: Trials, $F(2,96)=29.94, p<$ .001 . In addition, there was a significant Group $\times$ Trial interaction, $F(4,96)=2.70, p<.05$ (see Fig. 3). The interaction was assessed by performing a one-way ANOVA test on each trial. As expected, there was no significant difference among the groups on CCA1, $F(2,50)=0.90, p=0.41$ (see Fig. 3). On CCA2, using Bonferroni protection, the Control group had significantly higher intake than the GB-DT ${ }^{\mathrm{LiCl}}$ group (Control group vs. GB-DT ${ }^{\mathrm{LiCl}}, p<.001$; see Fig. 3), whereas it was not significantly different from the LT-DT ${ }^{\mathrm{LiCl}}$ group (Control group vs. LT-DT ${ }^{\mathrm{LiCl}}, p=.4$; see Fig. 3). In addition, there was a significant difference between the experimental groups (GB-DT ${ }^{\mathrm{LiCl}}$ vs. LT-DT ${ }^{\mathrm{LiCl}}, p<.05$; see Fig. 3). On CCA3, the Control group had higher takes than both experimental groups which did not differ from each other (Control group vs. GB-DT ${ }^{\mathrm{LiCl}}, p<.01$; vs. LT-DT ${ }^{\mathrm{LiCl}}, p<.01$; GB-DT ${ }^{\mathrm{LiCl}}$ vs. LT-DT ${ }^{\mathrm{LiCl}}, p=1$; see Fig. 3), reflecting the fact that water intakes were similar in both experimental groups after the second conditioning trial. In addition, each group was separately examined by using a repeated measures ANOVA. There was no effect of Trials in the control group: Control group, $F(2,32)=2.82, p=.07$, reflecting the fact that $\mathrm{NaCl}$ control group's water intakes were similar throughout conditioning, whereas water intake decreased across trials in both experimental groups: GB-DT ${ }^{\mathrm{LiCl}}, F(2,32)=17.97, p<.001$, and LT-DT ${ }^{\mathrm{LiCl}}, F(2,32)=20.09, p<.001$. A repeated measures ANOVA was applied to CCA2 and CCA3 for each experimental group. There was no main effect for Trials in GB$\mathrm{DT}^{\mathrm{LiCl}}$ group, $F(1,16)=0.34, p=.57$, whereas there was a main effect for Trials in LT-DT ${ }^{\text {LiCl }}$ group, reflecting the fact that there was a significant water intake reduction from CCA2 to CCA3, $F(1,16)=8.99, p<.01$.

\section{Retention}

Analyses of variance of intakes involved two betweensubjects factors, Groups (Control, GB, and LT) and Sex (Male and Female), and a within-subjects measure (Trials, 2).

There was a significant main effect for Group, reflecting the fact that, experimental groups had significantly lower intake than the control group: Groups, $F(2,48)=44.05, p<.001$ (see Fig. 3); however, a Trial $\times$ Group interaction was not observed, $F(2,48)=0.92, p=.41$. For the specificity test, there was no main effect for Groups (no difference in water intake among the groups when they drank from their maintenance bottles, $F(2,46)=1.57, p=0.22$ (see Fig. 3).

Table 2 Experimental groups $(N=17)$ and the tube configuration for Experiment 2

\begin{tabular}{|c|c|c|c|c|}
\hline Groups & Regular Tubes & $\mathrm{CS}$ & Injection & Abbreviation \\
\hline Control Group & Glass Bottle & Graduated tubes with dark-colored tape & $\mathrm{NaCl}$ & GB-DT ${ }^{\mathrm{NaCl}}$ \\
\hline \multirow[t]{2}{*}{ Experimental Groups } & Glass Bottle & Graduated tubes with dark-colored tape & $\mathrm{LiCl}$ & GB-DT ${ }^{\mathrm{LiCl}}$ \\
\hline & Graduated tubes with light-colored tape & Graduated tubes with dark-colored tape & $\mathrm{LiCl}$ & LT-DT ${ }^{\mathrm{LiCl}}$ \\
\hline
\end{tabular}


Development of aversion to graduated tubes with dark-colored tape by mice maintained on either glass bottles or graduated tubes with light-colored tape

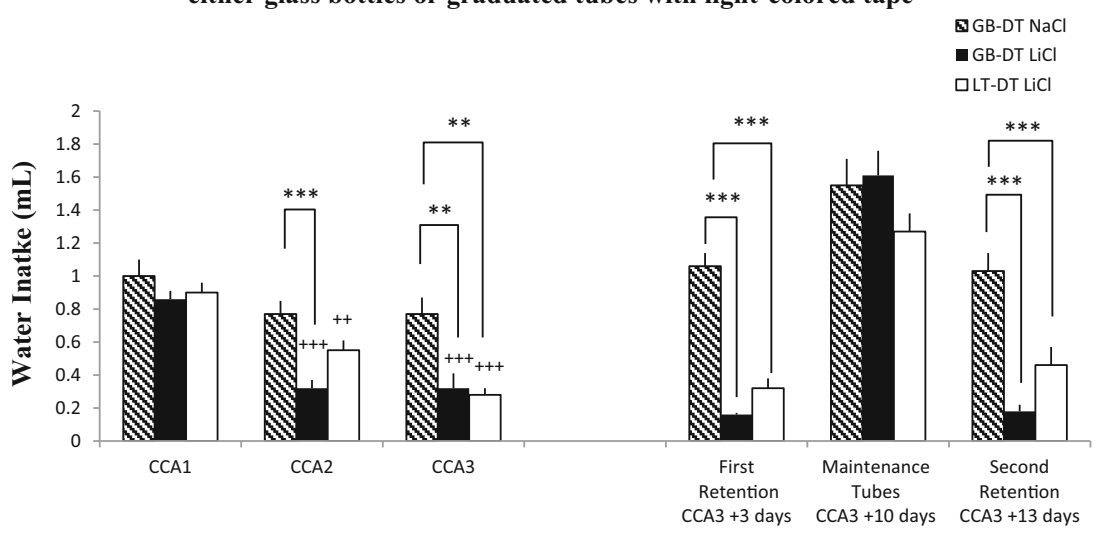

Conditioned Context Aversion: Acquisition, Retention and Specificity Trials

Fig. 3 B6/D2 AI mice maintained on either glass bottles (GB) or graduated tubes with light-tape (LT) were exposed to three conditioning trials when they drank from graduated tubes with dark-colored tape paired with injections of $\mathrm{LiCl}$ or $\mathrm{NaCl}$ (controls). Strong aversion was found with a single conditioning trial for GB-DT ${ }^{\mathrm{LiCl}}$ group, but two trials were required for LT-DT ${ }^{\text {LiCl }}$ group (see Table 2 for an explanation of abbreviations). During retention tests, both experimental groups showed high aversion to CS tubes, which was sustained for at least 13 days after CCA3. There was no difference in water consumption between experimental and control groups in the specificity test when animals drank from their maintenance containers. $* * p<.01$. ***p $<.001$, compared to control group intakes. $++p<.01 .+++p<.001$, compared to intake of same group on CCA1

\section{Discussion}

Experiment 1 provided evidence that that alterations in the cage environment (plastic vs. glass water bottles) served as CSs in an aversion conditioning paradigm. The findings of Experiment 2 showed that conditioned context aversion can be developed when even smaller alterationsin the home cage of a mouse are paired with illness (graduated tubes with dark vs. light tape). When there was a large difference between maintenance water container and CS (switching from glass bottle to a graduated tube with dark tape), the experimental groups exhibited strong aversion compared to controls after a single conditioning trial (see Fig. 3). However, when the difference between maintenance water containers and CS was smaller (switching from graduated tubes with light to dark tape), strong aversion required two conditioning trials (see Fig. 3).

Moreover, we provided more evidence that a change in the taste of water is not necessary to cause context aversion. Mice maintained on glass bottles or graduated tubes with lightcolored tape developed aversions to graduated glass tubes with dark-colored tape even though both glass bottles and graduated glass tubes had rubber stoppers and contained tap water.

Garcia and colleagues found that CTA's were retained for months after conditioning (Garcia et al., 1955). In Experiment 1 , the retention was tested 7 days after CCA3. In the present experiment, retention was demonstrated to be present at least 13 days after CCA3 in both experimental groups (see Fig. 3). Moreover, the results of the specificity test showed that there was no difference in consumption between experimental and control groups when animals drank from their maintenance bottles (see Fig. 3).

\section{Experiment 3}

The results of Experiments 1 and 2 demonstrated that mice developed strong aversions to both large and small alterations in their home cages when these were paired with illness. Furthermore, Experiment 2 showed that the conditioning was sustained for 13 days. The present experiment was designed to discover if context aversion could be formed when there is a substantial delay between CS and unconditioned stimulus (UCS), a characteristic known to be an important feature of conditioned taste aversion (Revusky \& Garcia, 1970). An additional aim was to evaluate the duration of retention.

\section{Method}

The subjects were $40 \mathrm{~B} 6 / \mathrm{D} 2 \mathrm{AI}$ mice (mean age 125 days, range: 120-130) from 17 different litters. Sex (15 male, 25 female) and litter membership was evenly distributed across the three experimental groups (10/group).

Before the experiment, mice were maintained on pint-sized translucent plastic bottles with blue plastic lids and metal spouts. They were then habituated to graduated tubes with a piece of light-colored tape near the spout for 7 days. Drink training proceeded as previously described. 


\section{Conditioning procedure}

During conditioning trials, water was presented to all mice in graduated tubes with a piece of dark-colored tape attached to the tube near the spout for 15 minutes. The two experimental groups were injected with $\mathrm{LiCl}$ immediately or 30 minutes after the graduated tubes were removed from cages: (LT-DT

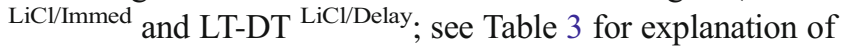
abbreviations). Control groups were injected with $\mathrm{NaCl}$ in the same manner as the LiCl groups: LT-DT ${ }^{\mathrm{NaCl} / \mathrm{Immed}}$ and LT-DT NaC/Delay (see Table 3).

Retention tests (42 minutes in duration) were carried out on three occasions (CCA3 $+7,+14,+21$ days). In each weekly trial, two consecutive daily tests were conducted: on the first day, half of the animals had access to water from a graduated tube with dark-colored tape (the CS); on the following day, these mice were presented with a graduated tube with a piece of light-colored tape (the maintenance tube); the other half were presented CS and maintenance tubes in the opposite order. This provided us with an opportunity to assess the total (dark-colored tape tube) and nonspecific aversion (light-colored tape tube).

\section{Results}

\section{Conditioning}

Analyses of variance of intakes involved three betweensubjects factors, Groups (Control vs. Experimental), CSUCS Interval (Immediate vs. Delay) and Sex (Male and Female) and a within-subjects factor (Trials, 3).

Experimental groups had significantly lower intakes than the control group Groups, $F(1,36)=14.79, p<.001$, and water intake levels decreased across Trials, $F(2,72)=22.86, p<.001$. In addition, a significant Group $\times$ Trial interaction, $F(2,72)=$ $33.74, p<.001$, and a Trial $\times$ Groups $\times$ CS-UCS Interval interaction, $F(2,72)=3.34, p<.05$, were observed (see Fig. 4). The interactions were assessed by performing a one-way ANOVA test on each trial. On CCA1, there was a significant interaction for the Groups $\times$ CS-UCS Interval, $F(1,39)=4.54, p<.05$, reflecting the fact that there was no significant differences between the responses of the immediate and delay control groups, whereas the LT-DT ${ }^{\text {LiC/Delay }}$ group drank less than the LT-DT
LiCl/Immed group. The difference was small (see Fig. 4) and difficult to understand because all groups had been treated in the same manner at that point in the experiment. On both CCA2 and CCA3, water intake, CCA2, $F(1,39)=8.63, p<.01$, and CCA3, $F(1,39)=44.05, p<.001$, was lower in the experimental groups compared to control (see Fig. 4). Repeated measures ANOVA showed that there was no main effect or interaction for the control group (control mice drank similar amounts on all three conditioning trials, $F(2,36)=0.49, p=.61$. However, in the analysis of the experimental groups, there was a main effect for Trials, $F(2,36)=60.54, p<.001$, and a significant Trials $\times$ CS-UCS Interval interaction, $F(2,36)=5.18, p<.05$, reflecting the finding that there were significant differences between the responses of the immediate and delay experimental groups from CCA1 to CCA3. To understand the reason for this interaction and the main effect, we conducted follow-up tests on the experimental groups. A repeated measures ANOVA was applied to CCA2 and CCA3. There was a main effect of Trials, $\mathrm{F}(1$, $18)=31.3, p<.001$, indicating that there was a significant water intake reduction from $\mathrm{CCA} 2$ to $\mathrm{CCA} 3$; however, there was no interaction for the Trials $\times$ CS-UCS Interval, $F(1,18)=0.006, p$ $=.94$, indicating that the LT-DT ${ }^{\text {LiC/Delay }}$ and LT-DT ${ }^{\text {LiC/Immed }}$ groups did not respond differently during CCA2 and CCA3 (see Fig. 4).

These findings also support the results of Experiment 2 that switching from graduated tubes with light-colored to darkcolored tape required two conditioning trials to obtain a strong aversion.

\section{Retention}

Analyses of variance of intakes involved four betweensubjects factors, Groups (Control vs. Experimental), CSUCS Interval (Immediate vs. Delay), CS Day (CS presented first or second within each week) and Sex (Male and Female) and as well as two within-subjects measures that were Trials (3) and Tubes (CS vs. Regular).

There was no significant difference associated with presenting the CS tubes first or second each week, so this factor was dropped from consideration.

A statistically significant Groups $\times$ Tubes $\times$ Trials interaction, $F(2,68)=3.37, p<.05$, was followed up by conducting

Table 3 Experimental groups $(N=10)$ and the tube configurations for Experiment 3

\begin{tabular}{lllll}
\hline Groups & Regular Tubes & CS & Injection & Abbreviation \\
\hline Control Groups & Graduated tubes with light-colored tape & Graduated tubes with dark-colored tape & NaCl (Immediate) & LT-DT ${ }^{\text {NaCl/Immed }}$ \\
& Graduated tubes with light-colored tape & Graduated tubes with dark-colored tape & NaCl (Delay) & LT-DT ${ }^{\text {NaCl/Delay }}$ \\
Experimental Groups & Graduated tubes with light-colored tape & Graduated tubes with dark-colored tape & LiCl (Immediate) & LT-DT LiCl/Immed $^{\text {Licl/Delay }}$ \\
& Graduated tubes with light-colored tape & Graduated tubes with dark-colored tape & LiCl (Delay) & LT-DT \\
\hline
\end{tabular}




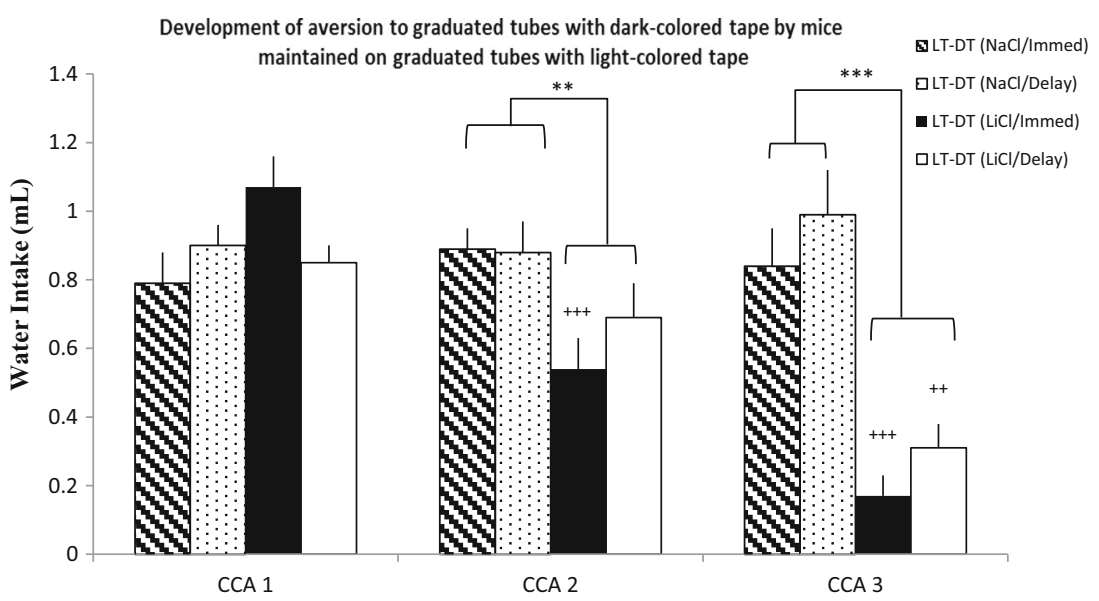

Fig. 4 B6/D2 AI mice maintained on graduated tubes with light-colored tape (LT) were exposed to three conditioning trials when they drank from graduated tubes with dark-colored tape (DT) paired with either injections of $\mathrm{LiCl}$ or $\mathrm{NaCl}$ immediately or 30 minutes later (delay). The aversion was clearly stronger on CCA3 for both immediate and delay groups. $* * p$ $<.01$. *** $p<.001$, compared to control group intakes. $++p<.01 .+++p<$ .001 , compared to intake of same group on CCA1 analyses within each group. There was no effect of Trials in the control group, $F(2,36)=0.96, p=.39$ (see Fig. 5a and b), reflecting the fact that $\mathrm{NaCl}$ control group's water intakes were similar throughout the retention trials; CS-UCS Interval, $F(1,28)=0.34, p=.56$; Tubes, $F(1,36)=0.82, p$ $=.38$; and no significant interaction between them, $F(2,36)=$ $0.75, p=.48$ (see Fig. 5a and b). In comparison, the LT-DT $\mathrm{LiCl/Immed}$ experimental group showed a main effect for Trials: water intake increased across trials, $F(2,16)=22.35, p<.001$; Tubes: mice drank less from their CS than from regular tubes, $F(1,16)=9.8, p<.05$. Similarly, in the LT-DT ${ }^{\text {LiCl/Delay }}$ group, there was a main effect for Trials: water intake increased across trials, $F(2,16)=17.36, p<.001$; Tubes: mice drank more from their regular than from CS tubes, $F(1,16)=8.88, p$ $<.05$ (see Fig. 5a and b).

As noted, there was no significant difference between intakes of immediate and delay control mice, so these data were combined to assess the effects of conditioning within each trial: conditioning resulted in significant aversions to both CS (Trial 1, both experimental groups; Trial 2, Immediate Group; see Fig. 5a) and maintenance tubes (Trial 1, both experimental groups; see Fig. 5b). On Trial 3, no effect was observed, presumably due to extinction.

The finding of a significant reduction in intake from maintenance tubes had not been suggested by the results of Experiment 2 but raised the issue of the role of sensitization in accounting for the substantial aversions seen during Trials 1 and 2 . To address this possibility, paired $t$ tests were conducted to compare intakes from $\mathrm{CS}$ and maintenance tubes: there was a significantly lower intake from CS vs. maintenance tubes in Trials 1 and 2 for the LT-DT ${ }^{\mathrm{LiCl} / \mathrm{Immed}}$ group (CS vs. maintenance, Week $1, t=2.58, d f=9, p<.05$ and Week $2, t=3.56, d f$ $=8, p<.001$, and for Trial 1 in the LT-DT ${ }^{\text {LiCl/Delay }}$ (CS vs. maintenance, Week $1, t=5.88, d f=8, p<.001$; Week $2, t=$
1.92, $d f=8, p=.09$ ). On Trial 3, there was no significant difference in intake between CS and maintenance tubes for either group (CS vs. maintenance, Week $3, t=0.084, d f=8$, $p=.94$ for LT-DT ${ }^{\mathrm{LiCl} / \mathrm{Immed}} ; t=0.52, d f=8, p=.62$ for LT-DT LiC/Delay). These results support a role for sensitization in the reduced intakes that were seen following conditioning, but specific factors are also important (see below).

To further compare total and nonspecific suppression of intake, we used a suppression index in which each individual animal's intake was subtracted from the control group mean for that trial, and the difference score was divided by mean control group intake, subtracted from 1 , and expressed as a percentage. ( $(1$ - [intake of the individual animal] / [mean intake of the control group] $) \times 100$ ). For example, $0 \%$ suppression indicates the same intake as control, $100 \%$ suppression indicates $0 \mathrm{~mL}$ intake (Nowlis, Frank, \& Pfaffmann, 1980). We found significantly greater total vs. nonspecific suppression in Trials 1 and 2 for the LT-DT ${ }^{\mathrm{LiCl} / \mathrm{Immed}}$ (Total vs. Nonspecific, Trial 1, $t=2.36, d f=9, p<.05$, and Trial $2, t$ $=4.75, d f=9, p<.001$; see Fig. $5 \mathrm{c}$ ). However, specific suppression had disappeared by Trial 2 for LT-DT ${ }^{\text {Licl/Delay }}$ group (Total vs. Nonspecific, Trial $1, t=5.76, d f=8, p<.001$, and Trial 2, $t=2.19, d f=8, p=.06$; see Fig. 5c). In Trial 3, consistent with extinction, there was no significant difference between total and nonspecific suppression within either of the conditioned groups (Total vs. Nonspecific, Trial 3, $t=1.29, d f$ $=9, p=.23$ for LT-DT ${ }^{\mathrm{LiCl} / \mathrm{Immed}} ; t=0.79, d f=8, p=.45$ for LT-DT $^{\text {LiCl/Delay; }}$ see Fig. 5c).

\section{Discussion}

These findings support the results of Experiment 2 that when the difference between novel and maintenance tubes was smaller (switching from graduated tubes with light-colored 
CS Tube (dark-colored tape) aversion following three conditioning trials with B6/D2 mice
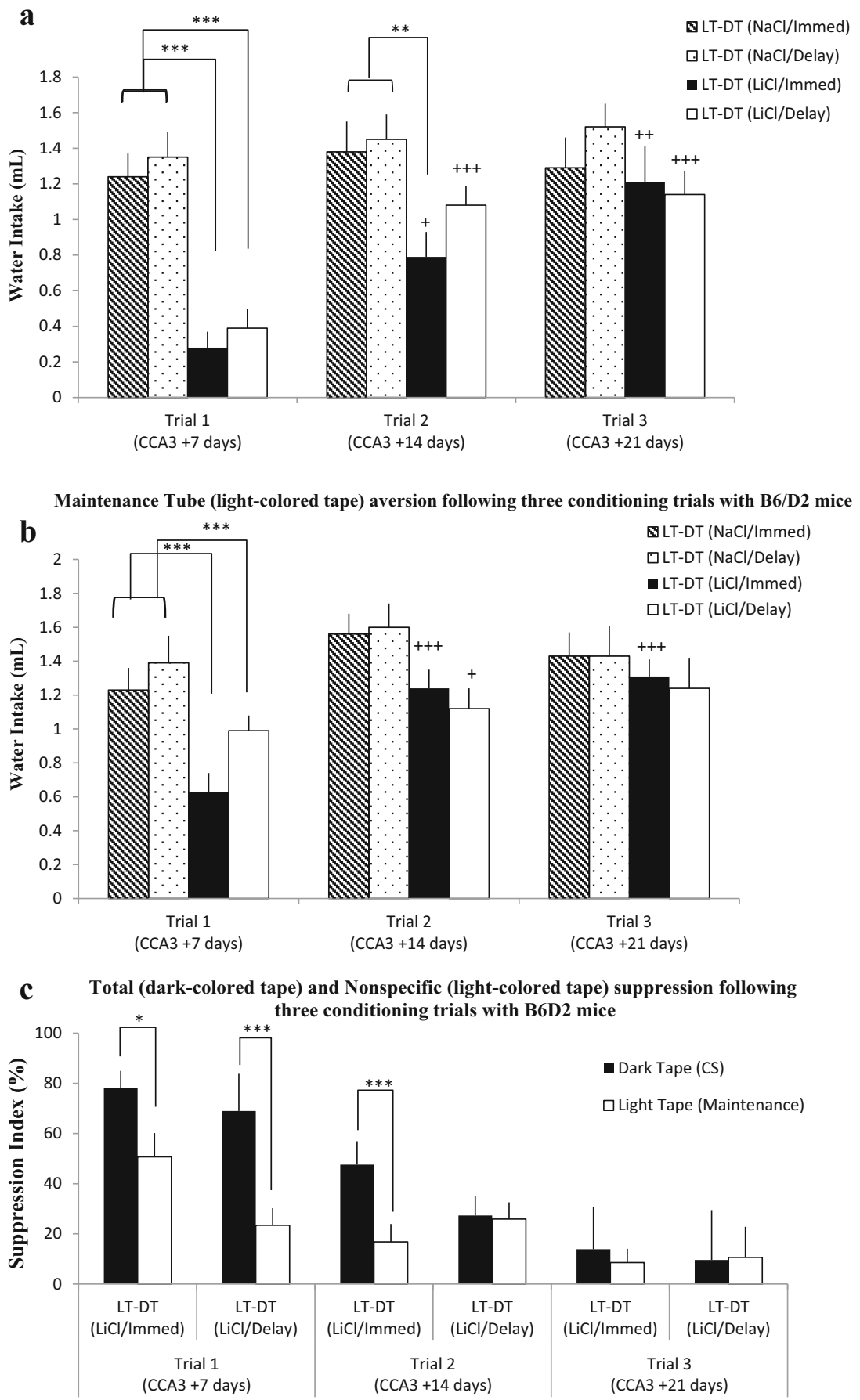

Fig. 5 a and b. Both total (CS Tube; graduated tubes with dark tape) and nonspecific (Maintenance Tube; graduated tubes with light tape) retention were tested at weekly intervals after CCA 3 . There was specific aversion (total greater than nonspecific aversion) in both Week 1 and 2 for the LTDT LiCl/Immed; however, specific aversion had disappeared by Week 2 for LTDT LiC/Delay group (see Table 3 for an explanation of abbreviations). By Week 3 , there was no evidence of both total or nonspecific aversion for both immediate and delay groups. ${ }^{* *} p<.01$. $* * * p<.001$, compared to control group intakes. $+p<.05 .++p<.01 .+++p<.001$, compared to intake of same group on Week 1. c. Both total and nonspecific retention were tested at weekly intervals after CCA 3. There was specific suppression (total greater than nonspecific suppression) in both Trials 1 and 2 for the LT-DT LiCl/Immed; however, specific suppression had disappeared by Trial 2 for LT-DT Lic/Delay group. By Trial 3, there was no evidence for both total or non-specific suppression for both immediate and delay groups. $* p<.05$. $* * * p<.001$, compared to suppression of same group on Week 1 and Week 2 
to dark-colored tape), a conditioned context aversion was nevertheless formed. In addition, it was shown that the context aversion could be formed when there was a substantial delay between CS and UCS. However, this aversion was weaker and retained for a shorter period of time. Another important finding of Experiment 3 was that nonspecific suppression of intake was clearly demonstrated when experimental mice drank from their maintenance tubes. This finding was somewhat surprising in that we did not find evidence for nonspecific suppression in Experiment 2. The tests for nonspecific suppression were conducted in different ways in the two experiments: in Experiment 2, the tests were conducted on a single day, 10 days after CCA3 with the presentation of the CS tubes being carried out on $\mathrm{CCA} 3+3$ and $\mathrm{CCA} 3+13$; in Experiment 3 , the tests for specific and nonspecific suppression were conducted on two consecutive days at weekly intervals with the different tubes being presented in a counterbalanced manner across the two days. In any case, while part of the suppression of intake in experimental mice on the first and second retention trials is likely due to sensitization to procedural factors such as water deprivation, the presence of the experimenter and other cues present in the experimental situation other than the differences between the graduated tubes, nevertheless, experimental mice drank significantly less from the tubes with dark tape than from tubes with light tape (the maintenance tubes). Thus, the decreased water intake in experimental mice from the CS tubes likely reflects both sensitization and specific aversion to the dark-colored tape.

\section{General discussion}

Conditioned context aversion is a well-established phenomenon, sharing with conditioned taste aversion the ability to form associations after a single conditioning trial (Garcia et al., 1955) as well as across substantial time intervals between CS and UCS (Garcia et al., 1966; Revusky \& Garcia, 1970). Theory and principles derived from the former studies have informed significant clinical issues in humans arising from conditioned nausea that often occurs when patients receive radiation and/or chemotherapy for cancer treatment (Andrykowski \& Redd, 1987; Stockhorst et al., 2006; Symonds \& Hall, 2002; Ursula et al., 2007). As noted, the bulk of the animal work has been conducted in laboratory rats because this species represents the bedrock upon which studies of learning and learning theory have been developed. An important aim of the present investigation was to develop a protocol for analysis of CCA in laboratory mice, a species which is increasingly used in neurobiological research and for which extensive resources have been developed to elucidate the role of specific genes and transgenes in the study of learning and memory (Ashe, 2001; Tecott, 2014). The protocols used in the reported experiments are somewhat different than those commonly used, which tend to employ multimodal or global CSs. In the present studies, discrete visual stimuli were used and all studies were conducted in the home cage. The results were quite clear: genetically heterogeneous laboratory mice with no known visual deficiency were able to form strong aversions after a single pairing of the CS with lithium chloride when the maintenance container was a plastic bottle and the CS a glass bottle (Experiment 1), or, when the maintenance container was a glass bottle and the CS, a graduated tube (Experiment 2), thus, paralleling an important component of the phenomenology of both CTA and CCA. It required two trials to form as strong an association when the difference between maintenance and CS tubes consisted of variation in the brightness of a piece of tape attached to the tubes (Experiments 2 and 3). Under the same juxtapositions between maintenance and CS tubes as those just described, aversive associations were also formed across a 30-min time interval, a finding also consistent with previous studies of both context and taste aversion conditioning (Garcia et al., 1966; Revusky \& Garcia, 1970). Retention was, however, short lived compared to that typically found in CTA paradigms, consisting of 2 weeks when CS-UCS pairing was immediate and 1 week across a 30-min CS-UCS delay. In more recent studies of retention duration using a similar paradigm (Kislal 2016, manuscript in preparation) longer retention has been found using a genetically different group of heterogeneous mice. All that can be said at present is that a range of CCA retention durations has been found in mice, and it will require additional studies to discover which are representative of this species.

Sensitization is an increase in the response to an innocuous stimulus due to exposure to a noxious stimulus (Domjan, 2009). In Experiment 3, an important role for sensitization in CCA was discovered. It did not account for all of the suppression of intake that was seen (see Discussion of Experiment 3), but its existence points to the importance of carrying out tests for sensitization in studies of conditioned context aversion.

All studies were conducted within the confines of the mouse's home cage, a situation that may make it possible for the subject to more easily detect changes in its environment. This may explain why small changes in the environment were able to form associations with the aversive UCS. It does seem plausible that increasing the signal (the CS) to noise (extraneous contextual stimuli) ratio in studies of context conditioning should have the benefit of enhancing experimental precision, and studies conducted within the confines of the home cage may be a means of attaining this objective. It could be asked whether associations between relatively minor changes in the environment (such as those employed in the present experiments) and illness fit properly under the rubric of context conditioning, which, as stated earlier, usually deals with larger, multimodal changes in the environment. Such a consideration may be important when considering the relevance of animal studies to the conditioned nausea that sometimes 
occurs among patients undergoing chemotherapy or radiation therapy in a contextually rich environment. On the other hand, one important objective of preclinical studies is to understand the neurobiological basis of this kind of learning and may be better pursued using discrete CSs, which provide more specific direction to the particular brain regions that may be involved in the processing of environmental stimuli. Genetically modified organisms (which can be more easily implemented using the mouse model) are also an important part of the experimental resources that can be martialed in this regard.

Finally, the usual interpretation of John Garcia's earliest observations (Garcia 1954; Reilly \& Schachtman, 2009) that rats avoided drinking from plastic bottles that had been paired with radiation because of the "plastic" taste of the water are challenged by the results of Experiment 1. It was impossible to precisely replicate Garcia's experiment because we were unable to measure water intake reliably when using plastic bottles. However, doing the reverse manipulation plastic (maintenance) to glass (CS), we found that decanting water from plastic bottles into glass bottles immediately before conditioning trials had no significant impact on the rate of acquisition of drinking from the CS paired containers. Furthermore, aversion was acquired after a single trial and was strongly retained. Thus, our results are consistent with the notion that Garcia's studies were an early demonstration of context aversion conditioning.

\section{References}

Andrykowski, M. A., \& Redd, W. H. (1987). Longitudinal analysis of the development of anticipatory nausea. Journal of Consulting and Clinical Psychology, 55(1), 36.

Ashe, K. H. (2001). Learning and memory in transgenic mice modeling Alzheimer's disease. Learning \& Memory, 8(6), 301-308.

Bertaina-Anglade, V., Tramu, G., \& Destrade, C. (2000). Differential learning-stage dependent patterns of c-Fos protein expression in brain regions during the acquisition and memory consolidation of an operant task in mice. European Journal of Neuroscience, 12(10), 3803-3812.

Blizard, D. A. (2007). Sweet and bitter taste of ethanol in C57BL/6J and DBA2/J mouse strains. Behavior Genetics, 37(1), 146-159.

Blizard, D. A., \& McClearn, G. E. (2000). Association between ethanol and sucrose intake in the laboratory mouse: Exploration via congenic strains and conditioned taste aversion. Alcoholism: Clinical and Experimental Research, 24(3), 253-258.

Boakes, R. A., Westbrook, R. E., Elliott, M., \& Swinbourne, A. L. (1997). Context dependency of conditioned aversions to water and sweet tastes. Journal of Experimental Psychology: Animal Behavior Processes, 23, 56-67.

Cusato, B., \& Domjan, M. (1998). Special efficacy of sexual conditioned stimuli that include species typical cues: Tests with a conditioned stimuli preexposure design. Learning and Motivation, 29(2), 152167.

Domjan, M. (2009). The principles of learning and behavior: Active learning edition. Boston, MA: Cengage Learning.

Garcia, J., Ervin, F. R., \& Koelling, R. A. (1966). Learning with prolonged delay of reinforcement. Psychonomic Science, 5(3), $121-122$.

Garcia, J., Kimeldorf, D. J., \& Koelling, R. A. (1955). Conditioned aversion to saccharin resulting from exposure to gamma radiation. Science, 122, 157-158.

Garcia, J. (1954). US Naval Radiological Defense Laboratory, Rpt. USNRDL-TR-19.

Nowlis, G. H., Frank, M. E., \& Pfaffmann, C. (1980). Specificity of acquired aversions to taste qualities in hamsters and rats. Journal of Comparative and Physiological Psychology, 94(5), 932.

Reilly, S., \& Schachtman, T. R. (2009). Conditioned taste aversion: Neural and behavioral processes. New York, NY: Oxford University Press.

Revusky, S., \& Garcia, J. (1970). Learned associations over long delays. The Psychology of Learning and Motivation, 4, 1-84.

Revusky, S., \& Parker, L. A. (1976). Aversions to unflavored water and cup drinking produced by delayed sickness. Journal of Experimental Psychology: Animal Behavior Processes, 2(4), 342.

Rodriguez, M., Lopez, M., Symonds, M., \& Hall, G. (2000). Lithiuminduced context aversion in rats as a model of anticipatory nausea in humans. Physiology \& Behavior, 71(5), 571-579.

Stockhorst, U., Steingrueber, H. J., Enck, P., \& Klosterhalfen, S. (2006). Pavlovian conditioning of nausea and vomiting. Autonomic Neuroscience, 129(1), 50-57.

Swank, M. W., Ellis, A. E., \& Cochran, B. N. (1996). C-Fos antisense blocks acquisition and extinction of conditioned taste aversion in mice. Neuroreport, 7(11), 1866-1870.

Symonds, M., \& Hall, G. (2002). Postinjection suppression of drinking is modified by the presence of conditioned contextual cues: Implications for both anticipatory and posttreatment nausea in humans. Animal Learning \& Behavior, 30(4), 355-362.

Tang, Y. P., Shimizu, E., Dube, G. R., Rampon, C., Kerchner, G. A., Zhuo, M., ... \& Tsien, J.Z. (1999). Genetic enhancement of learning and memory in mice. Nature, 401(6748), 63-69.

Tecott, L. H. (2014). The genes and brains of mice and men. The American Journal of Psychiatry, 160(4), 646-656.

Ursula, S., Paul, E., \& Sibylle, K. (2007). Role of classical conditioning in learning gastrointestinal symptoms. World Journal of Gastroenterology, 13(25), 3430-3437. 